\title{
O MITO DO DADO E A EPISTEMOLOGIA DE SELLARS
}

\author{
Marcelo Masson Maroldi ${ }^{1}$ \\ Universidade de São Paulo (USP) \\ https://orcid.org/0000-0002-0722-7107
}

\begin{abstract}
RESUMO:
Wilfrid Sellars é conhecido por seu famoso ataque a ideia de dados epistêmicos, isto é, a tese de que há algum conhecimento que é "dado" diretamente ao sujeito. De sua rejeição a dadidade, no entanto, seguem-se importantes ideias para uma discussão epistemológica. O objetivo deste artigo é apresentar a premissa geral do dado e da crítica de Sellars, e então discutir os conceitos extraídos desta crítica, introduzindo a epistemologia do próprio autor.
\end{abstract}

PALAVRAS-CHAVE: Sellars; Dado; Fundacionalismo; Coerentismo; Linguagem.

\section{THE MYTH OF THE GIVEN AND SELLARS' EPISTEMOLOGY}

\begin{abstract}
:
Wilfrid Sellars is well known for his famous attack on the idea of epistemic given, that is, the thesis that there is some piece of knowledge directly "given" to the subject. From that rejection, however, it emerges important ideas to epistemological discussions. The main objective of the present paper is to present the general premise of given and Sellars' criticism, and then to discuss the concepts extracted from such criticism by introducing Sellars' own epistemology.
\end{abstract}

KEYWORDS: Sellars; Given; Foundationalism; Coerentism; Language.

\section{Introdução}

Embora diferentes, as epistemologias racionalista, empirista e kantiana, em geral, aceitam um dualismo entre entidades não mentais

\footnotetext{
${ }^{1}$ Doutorando em Filosofia pela Universidade de São Paulo (USP), São Paulo - Brasil. Bolsista da Fundação de Amparo à Pesquisa do Estado de São Paulo (FAPESP). E-mail: marcelomaroldi@yahoo.com.br.
} 
(objetos materiais, tipicamente) e entidades mentais (ideias, pensamentos, representações etc.). Um objeto material está no espaço-tempo, portanto sujeito às leis da Física, e pode ser descrito por meio de características como cor, massa e localização. Uma entidade mental, porém, é não espacial e não se submete a tais leis. Atrelado a este distinção, encontra-se um princípio fundamental: o de que o sujeito tem acesso inquestionável às suas próprias entidades mentais. Ele pode duvidar do que se passa com seu corpo e outros objetos materiais, mas não deve rejeitar o conhecimento direito, por introspecção, do conteúdo de sua mente ou de suas ideias. Complementa o modelo a ideia de que os objetos mentais têm um conteúdo representacional, isto é, possuem certas propriedades que podem se referir a outros conteúdos, do mundo exterior ou mesmo outros estados mentais. A divisão entre o mental e o não mental e a adoção de teorias representacionais do conteúdo compõem o contexto teórico que faz necessária a noção de "dado", ou seja, tal cenário exige a presença do dado para explicar como o conhecimento daquilo que é exterior à mente pode ser possível.

O dado (given) é algo com valor epistêmico que é apreendido diretamente pelo sujeito. Trata-se de um conhecimento que não pressupõe outros conhecimentos, ele é autônomo, independente e não inferencial, e independe de processos cognitivos que os produza; apesar disso, o dado é indubitável e infalível. Consequentemente, ele pode servir como base para a edificação de mais conhecimento, ou seja, ele pode justificar conhecimentos que dele se seguem. Assim, uma razão frequentemente mencionada para aceitar a existência deste tipo de conhecimento é a de que é preciso haver um conhecimento essencial ou primeiro, caso contrário, o processo de justificar ou iniciar o saber geraria um regresso ao infinito. Portanto, deve existir algo que pode ser conhecido sem depender de nada.

Tanto o empirismo como o racionalismo moderno utilizaram versões do dado em suas explicações do conhecimento, aceitando, como dito, que os conteúdos mentais são os dados epistêmicos. Descartes, por exemplo, em suas Meditações Metafísicas, afirmou que o sujeito não pode duvidar de ter uma ideia clara e distinta de suas ideias, definindo que aquilo que é dado à mente serve como a pedra de fundação do saber. Autores como Locke, Hume e Kant sustentaram uma visão similar, baseando-se na infalibilidade das percepções da mente, argumentando que o conhecimento pode ser justificado pelo apelo direto aquilo que é dado à mente nas experiências individuais. Deste modo, a Epistemologia clássica propôs que se construísse o conhecimento sobre um tipo específico de dado, o conteúdo mental do sujeito.

Entretanto, esta estrutura teórica - que envolve dualismo, os dados e seu acesso imediato - começa a ser questionada no princípio do século XX. Inicialmente, o método introspectivo caiu em descrédito, substituído por abordagens científicas que valorizavam a observação e a experimentação. Nos anos de 1950, um dos grandes adversários do dualismo foi Ryle. The 
concept of Mind questiona a dificuldade em explicar como a mente e o corpo se relacionam e refuta a introspecção como método investigativo, defendendo que o acesso privilegiado não pode ser a origem do conhecimento. Como Ryle explica, o que o sujeito pode saber sobre si é o mesmo que ele pode saber sobre as outras pessoas, e o método para isso, em ambos os casos, é a observação do comportamento público (linguístico e não linguístico). Outro filósofo que atacou o modelo introspectivo e a teoria representacional da mente foi Wittgenstein, em sua fase madura. Como sugere McDowell (1994), o argumento da linguagem privada, presente nas Investigações Filosóficas, pode ser lido como uma rejeição geral a ideia de "dado" - neste sentido, a discussão sobre o "besouro na caixa" é bastante ilustrativa da questão. Um ataque completo contra os dados imediatos foi realizado por Austin em Sentido e Percepção. Contudo, foi Sellars quem formulou o mais conhecido e debatido ataque a dadidade ${ }^{2}$. O que ele chamou de o "mito do dado", em Empirismo e Filosofia da Mente, consiste em supor que algo pode possuir um valor epistêmico mesmo sem depender de nada e independentemente do modo como venha a ser adquirido pelo sujeito. Sellars acreditava que nem o racionalismo, nem o empirismo, nem Kant, tampouco Hegel ("o inimigo da imediatividade") teriam escapado da adesão a algum tipo de dado. Contudo, se ao longo da história vários tipos de entidades foram consideradas dadas (objetos materiais, universais, ideias inatas, primeiros princípios etc.), os conteúdos das sensações foram as mais recorrentes, e Sellars inicia contra estes conteúdos seu ataque, mais especificamente contra as teorias dos dados dos sentidos, muito populares no século XX.

\section{0 arqui-inimigo: os dados dos sentidos}

A doutrina geral, enunciada na sua generalidade, apresenta-se assim: nós nunca vemos, ou, de outro modo, percebemos (ou 'sentimos'), ou, de qualquer maneira, nunca percebemos ou sentimos diretamente objetos materiais (ou coisas materiais), mas somente dados dos sentidos (ou nossas próprias ideias, impressões, sensa, percepções sensíveis, perceptos, etc.) (AUSTIN, 2004, p.2).

Inúmeros autores utilizaram e defenderam versões da teoria dos dados dos sentidos, entre eles Moore, Russell, Price e Ayer. A expressão "sense data" foi popularizado por Russell, aparecendo pela primeira vez em

\footnotetext{
${ }^{2}$ Para uma análise detalhada da argumentação de Sellars contra o dado, veja James O'Shea (Wilfrid Sellars: naturalism with a normative turn. Malden: Polity, 2007) e deVries \& Triplett (2000).
} 
The Problems of Philosophy ${ }^{3}$. Posteriormente, ela passou a ser utilizada por todos que desejavam designar os dados obtidos diretamente da experiência sensorial.

Um dos defensores dos dados dos sentidos foi Price. O ex-professor de Sellars inicia seu livro Perception com o capítulo The Given, onde apresenta sua visão sobre a experiência perceptiva iniciando com uma passagem em que ele descreve a percepção de um tomate ${ }^{4}$. Segundo Price, se o percipiente não pode estar absolutamente seguro de perceber um tomate, tampouco pode duvidar de que percebe algo vermelho e redondo que lhe é dado à consciência de maneira direta. Como o que é percebido pode não ser realmente o tomate (o sujeito poderia perceber algo vermelho e redondo, por exemplo, por estar alucinando), deve ser um dado sensível, que é, portanto, independente do objeto em questão (neste caso, do tomate).

Outro defensor da teoria dos dados dos sentidos é Ayer: "For to say that an object is immediately 'given' is to say merely that is the content of a sense-experience" (2001, p. 128). Segundo Ayer, no entanto, por que alguém deveria acreditar que não se percebe diretamente objetos, mas somente dados dos sentidos? Uma razão é oferecida pelo argumento da ilusão. Ele se refere à percepção que discorda da realidade do objeto, por exemplo, quando uma moeda circular parece elíptica dentro da água - Ayer (1961) enumera diversos exemplos. Ou seja, o objeto pode parecer diferente ao sujeito a partir de condições como a posição da fonte de luz ou do meio em que a luz se propaga. Se o objeto, nestas situações atípicas, pode parecer de um jeito que ele não é, então, nestas situações, não se percebe o que o objeto é, mas alguma outra coisa. Ora, se o objeto parece ter uma propriedade que na realidade ele não tem é porque se percebe alguma outra

3 "Let us give the name of 'sense-data' to the things that are immediately known in sensation: such things as colours, sounds, smells, hardnesses, roughnesses, and so on. We shall give the name 'sensation' to the experience of being immediately aware of these things. Thus, whenever we see a colour, we have a sensation of the colour, but the colour itself is a sense-datum, not a sensation. The colour is that of which we are immediately aware, and the awareness itself is the sensation" (RUSSELL, 1997, p. 12).

4 "When I see a tomato there is much that I can doubt. I can doubt whether it is a tomato that I am seeing, and not a cleverly painted piece of wax. I can doubt whether there is any material thing there at all. [..] But that something is red and round then and there I cannot doubt. Whether the something persists even for a moment before and after it is present to my consciousness, whether other minds can be conscious of it as well as I may be doubted. But that it now exists, and that $I$ am conscious of it - by me at least who am conscious of it this cannot possibly be doubted. And when I say that it is 'directly' present to my consciousness, I mean that my consciousness of it is not reached by inference, nor by any other intellectual process (such as abstraction or intuitive induction), nor by any passage from sign to significate. There obviously must be some sort or sorts of presence to consciousness which can be called 'direct' in this sense, else we should have an infinite regress. Analogously, when I am in the situations called 'touching something', 'hearing it', 'smelling it', etc., in each case there is something which at that moment indubitably exists a pressure (or prement patch), a noise, a smell; and that something is directly present to my consciousness" (PRICE, 1932, p. 3). 
coisa que possua tais propriedades, os dados dos sentidos. A partir disso, Ayer expande o argumento para mostrar que, mesmo em situações consideradas normais, o que é percebido é sempre um dado do sentido.

Embora o argumento da ilusão seja o mais utilizado pelos teóricos dos dados dos sentidos ${ }^{5}$, estes também usaram em seu favor outros argumentos. Uma pequena mudança no argumento da ilusão gera o argumento da variação perceptiva. Russell (1912) afirma que, caso o sujeito esteja tendo experiências sensoriais de uma mesa e se mova de posição, a experiência sensorial também mudará ${ }^{2}$. Se estas variações do sujeito produzem variações em sua percepção, e objetos não mudam de aparência, as qualidades experienciadas não são exclusivas dos objetos, mas de algo presente na mente de quem os percebe. Conclui-se que a percepção não depende unicamente do objeto, mas de dados sensíveis processados na mente do sujeito que percebe. Outro argumento usual é o argumento da alucinação, evocado nos casos em que o sujeito tem uma experiência perceptiva que ele considera real mesmo que o objeto não esteja presente. Ora, se o sujeito pode ter uma experiência perceptiva na ausência do objeto, sem distingui-la da percepção na presença do objeto, a falsa percepção compartilha as mesmas propriedades da verdadeira percepção. Logo, estas propriedades não podem estar nos objetos, mas em algo na experiência de quem percebe, ou seja, a percepção exige dados dos sentidos percebidos pela mente.

Estes e outros argumentos, usados por empiristas contemporâneos, advogam pela existência de dados epistêmicos que exigem apenas uma mente consciente que os perceba. Estes dados proporcionam um ponto de contato confiável da mente com o mundo exterior, sendo suficientes para fundar uma teoria epistemológica; esta é a tese que Sellars se dedica a refutar. Os dados dos sentidos são um modelo de epistemologia baseada no conceito de dado que precisa ser rejeitado.

\section{A crítica de Sellars ao dado}

Segundo Sellars, se na metade do século XX cresciam os ataques ao dado, estas críticas, em geral, atacavam apenas as teorias dos dados dos sentidos. E, o que era pior, as críticas erravam ao considerar que o problema com aquelas teorias era o fato de que elas aceitavam a existência de episódios internos. Ora, o problema não é defender a existência de tais episódios, mas a noção teórica de "dado" que as acompanha. Segundo Sellars, o teórico dos dados dos sentidos confunde os sentidos epistêmico e

\footnotetext{
${ }^{5}$ Cf. Moore (The Refutation of Idealism. Mind, 12, 1903) e (A Defense of Common Sense. In: MUIRHEAD, J. H. (Ed.). Contemporary British Philosophy. London: Allen and Unwin, 1925), Russell (1912) e Price (1932).

${ }^{6}$ Em An Enquiry concerning Human Understanding (Oxford/New York: Oxford University Press, 1999), David Hume propõe um argumento similar (veja XII.1).
} 
não epistêmico da experiência, devido a sua incapacidade de distinguir entre sentir e perceber, o conhecimento de fatos e de particulares, o conhecimento de conteúdos proposicionais e não proposicionais e, finalmente, sua falha ao diferenciar as capacidades aprendidas do sujeito daquelas que não são aprendidas.

Para explicar a fundação do conhecimento baseando-se em um saber não inferencial de questões de fato, como deseja o teórico do dado, é preciso admitir que aquilo que é experienciado ou são particulares ou são fatos. Se o dado for experimentado como um conhecimento de particulares na forma não proposicional, ele não terá condições de sustentar a predicação e nem possuirá quaisquer relações conceituais, assim, ele não pode ter um papel epistêmico para o sujeito; portanto, se particulares não proposicionais é que são sentidos, sentir não é conhecer. Desde que a apreensão de particulares na forma não proposicional não pode ser epistêmica, o empirista pode então afirmar que o conhecimento de particulares pressupõe alguma forma proposicional; neste caso, porém, o dado não será independente. Portanto, ou sentir não é conhecer ou o que é conhecido são fatos. O teórico dos dados dos sentidos, neste memento, poderia assumir que o conhecimento perceptivo se baseia em apreensão direta dos fatos. Isso, no entanto, não o deixará confortável uma vez que ele admite que a apreensão dos dados dos sentidos não pressupõe aprendizagem, ou seja, ele admite que "X sente o conteúdo sensorial S" ou "X sabe não inferencialmente que $S$ é vermelho" é uma habilidade não adquirida. Mas saber que "algo é tal e tal", isto é, a subsunção de um particular sob um universal, envolve, em alguma medida, aprendizado e uso de conceitos, já que fatos tem a forma "x é F" ou "eu sei que x é F", que dizem algo sobre algo. Segundo Sellars, diante destas dificuldades, os teóricos dos dados preferem manter suas premissas de que "sentir é um conhecer $e$ que são particulares que são sentidos" (SELLARS, 2008, p. 26), apoiando-se, em razão disso, em três proposições conflitantes:

(i) $\mathrm{X}$ sente o conteúdo dos sentidos $\mathrm{S}$ implica $\mathrm{X}$ sabe não inferencialmente que $S$ é vermelho [por exemplo].

(ii) A habilidade de sentir conteúdos dos sentidos é não adquirida.

(iii) A habilidade de saber fatos da forma $\mathrm{X}$ é $\Phi$ é adquirida.

Portanto, a dificuldade em compreender a distinção entre particulares e fatos, forma proposicional e não proposicional e conhecimento aprendido e inato empurra o adepto dos dados dos sentidos a uma inconsistência. Para Sellars, a tríade é insustentável devido à incapacidade de seu defensor diferenciar o caráter epistêmico e não epistêmico da experiência, afinal, "não 
há razão para supor que ter a sensação de um triângulo vermelho seja um fato cognitivo ou epistêmico"(SELLARS, 2008, p. 31). ${ }^{7}$

Uma maneira que o teórico do sentido poderia encontrar para contornar estas dificuldades é adotar uma forma do fundacionismo que toma a aparência como algo dado ao percipiente ("x parece $\mathrm{F}$ a $\mathrm{S} "$ "). Neste caso, o conhecimento das aparências é aquilo que é dado. Sellars menciona esta possibilidade argumentativa porque dela extrai algumas consequências positivas importantes. Para isso, considere três possibilidades para o uso de "parecer", admitindo, como referência, o conteúdo proposicional "que x, lá, é vermelho" em todos os casos.

(a) Ver que $\mathrm{x}$, lá, é vermelho.

(b) Está parecendo que x, lá, é vermelho.

(c) Está parecendo como se houvesse um objeto vermelho lá.

As três possibilidades acima diferem pelo fato de (a) estar formulada de maneira a envolver um endosso da ideia de que "x, lá, é vermelho", enquanto que em (b) esta ideia está apenas parcialmente endossada e, em (c), ela não está endossada. Sellars aprofunda a discussão através de uma breve história envolvendo um vendedor de gravatas e o processo de aquisição da técnica necessária para descrever as cores das gravatas em condições de iluminação distintas. A história mostra que o entendimento da aparência de objetos já é uma capacidade conceitual, adquirida em circunstâncias diversas (com luz, sem luz etc.) através das quais as experiências perceptivas podem vir a ser justificadas pelo sujeito. Assim, o ponto central da tese de Sellars é a de que os relatos de aparência combinam as declarações referentes às experiências sensíveis juntamente com o endosso e a justificação destas experiências. Embora os relatos (a), (b) e (e) repousem sobre um conteúdo não proposicional (uma sensação de vermelho), eles possuem, também, um conteúdo proposicional ("que x é vermelho") que envolve uma capacidade conceitual adquirida em experiências distintas com o uso da linguagem pública. A lógica do parece, portanto, explicita a diferença entre é e parece:

O conceito de parecer verde, a habilidade de reconhecer que algo parece verde, pressupõe o conceito de ser verde, e que o último conceito envolve a habilidade de dizer o que os objetos coloridos são olhar para eles - que, por sua vez, envolve saber em quais circunstâncias colocar um objeto se

\footnotetext{
${ }^{7}$ Em outro lugar, Sellars (1991, p. 336) afirma: "Sensations are no more epistemic in character than trees or tables, and are no more ineffable. They are private in the sense that only one person can notice then; but they are public in the sense, in principle, I can state the same facts about your sensations that you can report, and can state the same facts about your sensations that I can report about my own".
} 
queremos determinar sua cor olhando para ele (SELLARS, 2008, pp. 49-50, grifo meu).

Teóricos dos dados que se baseiam no discurso da aparência não compreendem que o discurso sobre ser algo é anterior ao discurso sobre parece ser algo, ou seja, que afirmar que algo "parece $\mathrm{x}$ " já é situar a experiência a partir do conceito de "ser X", o que nega a prioridade epistêmica da aparência e instaura a dimensão conceitual da experiência sensível. Uma sensação de um objeto vermelho tem um conteúdo sensível de vermelho, mas não é o conhecimento do objeto como sendo "de vermelho". Portanto, a sensação não oferece dados que dispensem a capacidade do sujeito de reconhecer e aplicar conceitos em todas as experiências. A prática de relatar uma sensação precisa acompanhar a prática de relatar esta mesma experiência com uma aplicação de conceitos e sua justificativa, o que requer a compreensão do conceito a ser justificado pelo sujeito da experiência, que assume, assim, um compromisso com a aplicação do conceito. A percepção, diferente da sensação, envolve a conceituação e as suas consequências. Sendo assim, o conhecimento é uma questão normativa e o foco de sua investigação deve recair sobre as capacidades conceituais e de justificação que estão envolvidas, até mesmo na percepção de objetos.

Dito isso, fica claro que os adeptos dos dados do sentido erram porque confundem o papel causal presente na experiência observacional com o papel conceitual que envolve tal experiência, ou seja, aqueles que usam o dado para fundar o conhecimento desconhecem a natureza da experiência epistemológica. Eles confundem o ato sensitivo com o ato cognitivo, a experiência imediata (não epistêmica) com um pensamento (epistêmico, conceitual). As experiências sensoriais oferecem aos sentidos objetos que não deves ser confundidos com objetos de conhecimento. Reconhecer uma experiência sensorial como um episódio de conhecimento envolve a capacidade de responder a esta experiência aplicando conceitos e sendo capaz de justificar tal aplicação, se necessário. Portanto, episódios de conhecimento envolvem a capacidade de situar a experiência em um jogo linguístico e racional; o conhecimento sempre envolve um discurso semântico e intencional. Portanto, ao trazer à discussão epistemológica as exigências de aplicação e de justificação conceitual, Sellars mostra que algo simplesmente dado é um mito. Antes, porém, de aprofundarmos o aspecto positivo da crítica ao dado e a nova epistemologia que dela emerge, recapitulemos a discussão até aqui, apresentando, em seguida, a forma geral do argumento contra o dado.

$\mathrm{O}$ argumento de Sellars contra os dados dos sentidos pode ser generalizado para contemplar qualquer explicação epistemológica que requer algo dado. A ideia principal é a de que o epistêmico exigem relações conceituais e, portanto, ocorre somente com entidades linguísticas na forma de proposições. E, no entanto, se o dado precisa possuir conexões 
conceituais, ele não pode ser epistemicamente independente. Uma maneira esquemática de apresentar a estrutura geral do argumento contra a dadidade é, portanto, a seguinte. ${ }^{8}$

As condições iniciais que a doutrina do dado exige são:

a. A doutrina do dado impõe que algo é um dado $\mathrm{X}$ se for epistemicamente independente e possuir um valor epistêmico.

b. Admite-se que possam existir dados na forma não proposicional ou na forma proposicional.

1. Contesta-se, primeiro, o dado em sua forma não proposicional (por exemplo, dados dos sentidos, universais, os próprios objetos materiais etc.):

1.1. Um dado $X$ possui valor epistêmico em si mesmo se pode servir como uma razão para Y.

1.2. X serve de razão para $Y$ se puder servir de premissa para $Y$.

1.3. X só é premissa de um argumento se tiver a forma proposicional.

1.4. Portanto, o que é não proposicional não pode ter valor epistêmico.

1.5. Logo, o que é não proposicional não serve como dado.

2. A seguir, rejeitam-se os dados em sua forma proposicional (por exemplo, primeiros princípios, proposições, proposições perceptivas etc.):

2.1. Um dado da forma proposicional $X$ deve ser epistemicamente independente.

2.2. Todo X é inferencial (2.2.1) ou não inferencial (2.2.2).

2.2.1. Nenhum $X$ inferencial é epistemicamente independente.

2.2.1.1. Nenhum $X$ inferencial é dado.

2.2.2. $\quad \mathrm{X}$ na forma não inferencial precisa ser justificado pelo sujeito $\mathrm{S} ; \mathrm{S}$ precisa saber que $X$ é condição de justificação.

2.2.2.1. Portanto, não há $X$ não inferencial epistemicamente independente.

2.2.2.2. Portanto, $X$ não pode independente.

2.2.3. Logo, o que é proposicional não serve como dado.

3. O que nos leva a concluir que nada pode ser admitido como possuindo um valor epistêmico intrinsecamente dado ao sujeito.

\section{Os espólios do mito de dado}

Segundo Sellars, a noção de "dado" resulta de uma confusão entre o modo como se experiencia o mundo e o modo como essa experiência é classificada e inserida em um esquema conceitual. A confusão nos leva a repensar a questão de como algo se torna conhecimento. Para entender como algo adquire um valor epistêmico é preciso de mais do que objetos ou

\footnotetext{
${ }^{8}$ Este esquema geral da crítica ao dado é uma versão simplificada daquele encontrada em deVries \& Triplett (2000).
} 
entidades sendo dadas, é preciso de contexto e de linguagem. Fora do espaço conceitual e de suas relações não há conhecimento, ou seja, algo adquire um valor de conhecimento quando é inserido na estrutura de justificação conceitual do sujeito - nunca fora, ou antes, de pertencer a tal estrutura. Assim, ao invés de recorrer ao dado, Sellars sugere uma Epistemologia baseada na classificação inferencial das experiências do sujeito, um funcionalismo de conceitos na forma linguística que ocorre em uma estrutura cognitiva chamada de "espaço lógico das razões". Isto é, da critica ao dado surge uma discussão sobre o uso de conceitos e a sua justificação normativa que, como vimos, parte de duas ideias. A primeira, a de um sentir não conceitual, que ocorre sem qualquer processo de aprendizado ou de aplicação de conceitos. A segunda, a ideia de um perceber já conceitual, que envolve o domínio de relações inferenciais e, portanto, envolve a linguagem. Estas ideias alcançam seu desenvolvimento na breve descrição que Sellars faz do nominalismo psicológico.

\section{O nominalismo psicológico e o espaço lógico das razões}

Após recusar o caráter epistêmico intrínseco do dado, Sellars inicia uma curta análise dos empiristas modernos, começando por Locke e Berkeley. Para ele, estes autores, ao negligenciarem o aspecto conceitual, necessário para a ocorrência de episódios de conhecimento, recorrem ao dado pressupondo que nós "temos uma habilidade não adquirida de estarmos conscientes de repetíveis determinados" (SELLARS, 2008, p. 68). Hume também admite esta capacidade inata de reconhecer particulares como sendo dados simplesmente em virtude de experimentarmos sensações. Contudo, em A Treatise of Human Nature, Hume afirma que uma ideia particular se torna geral quando é associada a um termo geral ${ }^{9}$, isto é, a consciência de particulares se assenta na associação de palavras com particulares que são semelhantes. Porém, esta associação envolve a ocorrência de particulares frente à consciência de que eles são semelhantes e, assim, embora Hume esteja um passo adiante de Locke e Berkeley, continua preso a uma versão do dado. Entretanto, Sellars acredita que com uma "leve torção" em Hume é possível alcançar uma visão "radicalmente diferente". Segundo Sellars, não se trata de relacionar particulares conhecidos com uma palavra, não se associa símbolos a uma classe de objetos semelhantes imediatamente conscientes somente por experiêncialos. Se a capacidade de formar ideias vem da habilidade de associar palavras com classes de particulares, esta associação não precisa ser mediada pela consciência. Como resultado, pode se supor que a ligação entre a experiência imediata consciente e as palavras desaparece - a consciência de

\footnotetext{
9 "A particular idea becomes general by being annexed to a general term; that is, to a term, which from a customary conjunction has a relation to many other particular ideas, and readily recalls them in the imagination" (HUME, 2007, I.1.7).
} 
particulares não precisa ser dada - e é possível aceitar simplesmente a ideia de uma associação de palavras e objetos do mundo - como entre "vermelho" e objetos físicos vermelhos -, sem precisar aceitar a associação entre "vermelho" e uma classe dada de particulares vermelhos privados. Torcendo Hume, então, chega-se ao "nominalismo psicológico", que afirma:

Toda consciência de tipos, semelhanças, fatos, etc., em suma, toda consciência de entidades abstratas - na verdade, toda consciência mesmo de particulares - é uma questão linguística. De acordo com essa perspectiva, nem mesmo a consciência desses tipos, semelhanças e fatos pertencentes às assim chamadas experiências imediatas é pressuposta no processo de aquisição do uso de uma linguagem (SELLARS, 2008, p. 68).

A formulação do nominalismo psicológico indica que toda experiência epistêmica ocorre "como sendo manifestação de conexões associativas de tipos palavra-objeto e palavra-palavra" (SELLARS, 2008, p. 68), ou seja, os episódios de "algo como algo" são sempre fundados em associações de palavras com objetos físicos ou com outras palavras. Assim, adquirir um conhecimento não é associar um símbolo a um conteúdo mental consciente, dado, mas aprender a relacionar as experiência e a linguagem, isto é, classificar as experiências segundo as categorias semânticas da linguagem. Portanto, a linguagem não adquire seu significado de algo dado à mente ou à consciência (uma versão do mito do dado); ao contrário, a linguagem fornece à mente (capacidade cognitiva) as suas próprias categorias estruturantes (cf. Maroldi, 2014). Deste modo, o nominalismo psicológico e a epistemologia exigem o uso de uma linguagem pública ou, em outras palavras, Sellars propõe que a "consciência epistêmica" é uma questão linguística. Por "consciência epistêmica", deve-se entender uma consciência conceitual, a habilidade de classificar as experiências aplicando conceitos, na forma linguística, e compreendendo suas relações com outros conceitos pertencentes à estrutura em que tais conceitos existem.

De fato, Sellars distingue duas capacidades cognitivas, ambas classificatórias, embora somente uma delas seja epistêmica no sentido acima. A senciência é a capacidade que um agente possui de reagir a estímulos classificando-os, mas sem envolver conceituação - por exemplo, treinando um papagaio a emitir o som "Isto é vermelho" na presença de objetos vermelhos ou programando um termostato para produzir o som "Está $30^{\circ} \mathrm{C} "$ quando tal temperatura é atingida. A sapiência (que pode ser entendida como a própria capacidade racional) é um estado cognitivo complexo que exige classificar os estímulos aplicando e justificando a aplicação de conceitos. Portanto, a diferença entre estas duas capacidades não consiste na habilidade de relatar adequadamente (classificar) a experiência, mas em sustentar o relato oferecendo razões para tal. Embora o papagaio responda adequadamente à experiência sensível, ele não 
compreende as condições e consequências de sua resposta. Isto é, apesar de corretamente produzir o som "Isto é vermelho" diante de objetos vermelhos, o papagaio não aplica o conceito de "vermelho" por não ser capaz de dominar as relações que envolvem este conceito - por exemplo, afirmar "Isto é vermelho" na presença de objetos vermelhos e, também, "Isto é não azul", como uma consequência da relação entre "vermelho" e "azul". Portanto, para que algo seja considerado como um conhecimento precisa de uma articulação que se estabelece como um jogo, com regras que correspondem às relações de uso permitidas na rede de conceitos que regem aquele jogo. Admitindo que a classificação conceitual da experiência está além da mera capacidade respondente, ao ocupar uma posição na estrutura racional do sujeito, Sellars está propondo uma Epistemologia que depende da capacidade de identificar os papéis desempenhados por "conceitos" no raciocínio do agente, ou seja, ele oferece uma teoria racionalista e funcional dos conceitos. Ser racional, neste sentido, é encontrar-se em meio ao espaço lógico das razões: "O ponto essencial é que, ao caracterizar um episódio ou um estado como aquele de saber, não estamos dando uma descrição empírica de tal episódio ou estado; nós o estamos situando no espaço lógico das razões, do justificar e ser capaz de justificar o que se diz" (SELLARS, 2008, p. 71).

Aplicar um conceito, sendo capaz de defender e sustentar tal aplicação ao mostrar sua articulação, é o mesmo que oferecer uma razão. O jogo de dar e pedir por razões é, assim, a própria prática de usar, endossar e justificar conceitos; é o que Sellars entende por "epistêmico". Algo pode ser aceito como conhecimento se, e somente se, sustentar-se num discurso válido neste espaço lógico, racional. Porém, esta não é uma habilidade inata, pelo contrário, deve ser conquistada junto à comunidade durante o aprendizado da linguagem pública. Dar e exigir razões depende, então, do reconhecimento e da adesão ao espaço de normas vigentes da comunidade na qual se cresce e vive, normas estas estabelecidas na linguagem e em suas relações. $\mathrm{O}$ adulto que domina o uso da linguagem pública pode fornecer o contexto (condições e consequências) na qual sua reação frente ao estímulo foi produzida, dando uma justificativa confiável para ela. Há, entretanto, o requisito de que o próprio sujeito desempenhe um papel ativo no exercício de tais capacidades conceituais e racionais; não basta responder ao mundo, como um papagaio responde, porém, responder ao mundo de certa maneira, assumindo determinados compromissos demarcados pela linguagem e as relações que envolvem o sujeito e o mundo. Desta maneira, um "conceito" é um mediador das relações do sujeito com o mundo, ou seja, conceitos são como disposições de um sujeito especificadas por seu papel ou função em uma estrutura linguística e inferencial que entremeia a relação deste sujeito com o mundo, com outros indivíduos e assim por diante.

O espaço lógico das razões é uma estrutura linguística, conceitual, de justificação e endosso, normativa e inferencialmente articulada. Como 
vimos, o nominalismo psicológico se refere a um entendimento da racionalidade e do conhecimento totalmente vinculada à questão linguística. Ele nega que há uma forma de consciência racional plena do espaço lógico que é anterior à aquisição da linguagem, isto é, o jogo das razões só é possível quando se aprende a usar uma linguagem. Contudo, isso não significa somente exigir o domínio de palavras para possuir conceitos, mas, e especialmente, possuir a habilidade de colocar os conceitos (palavras) uns contra os outros, de posicioná-los em uma "rede" representada linguisticamente. Assim, o uso de conceitos nunca é direto ou dado; ele precisa ser conquistado, adquirido, o que é alcançado junto à comunidade ao aprender a utilizar a linguagem pública e as relações conceituais que ela estabelece. Dar razões e conhecer (inclusive o conhecimento de estados mentais) envolve uma dimensão intersubjetiva.

Um conhecimento só precisa ser aceito se sustentar-se ou se for justificado por um discurso adequado à estrutura do espaço lógico a que pertence; e a própria justificação é uma aplicação conceitual. Assim, o uso de conceitos, seu endosso e sua justificação são todas discussões normativas. No entanto, a principal característica do espaço lógico é a sua articulação inferencial, que confere ao quadro conceitual uma estrutura em termos de permissões, consequências e incompatibilidades. Conhecer, dominar um significado ou possuir um conteúdo é lidar com os conceitos de um ponto de vista funcional, mais precisamente, o domínio de sua função inferencial. Aplicar conceitos e usar palavras, dar razões e justificá-las, é mover-se em um espaço de relações inferenciais, isto é, relações baseadas em inferências com condições de sustentar o uso daquele conceito ou servir como uma razão. Um conceito (ou razão) só é compreendido a partir da compreensão de suas relações inferenciais, ou seja, dominar um conceito (ou uma razão) é estar apto a usá-lo considerando suas ligações interconceituais. Por isso, quem endossa o uso de um conceito simultaneamente endossa (ao menos algumas de) suas consequências e rejeita (ao menos algumas de) suas incompatibilidades. Conceitos sem relações inferenciais são sem significado, são uma versão do mito do dado.

É importante frisar que Sellars não está propondo uma explicação da aquisição ou da natureza dos conceitos e da linguagem. Ele está afirmando que é permitido usar termos como "epistêmico", "razão" e "significado" quando se aprende as regras que regem os jogos linguísticos em que tais termos são usados, e isso é possível quando se adquire uma linguagem e se compreende as exigências de justificação e de uso normativo de palavras e de conceitos. Mesmo a experiência perceptiva precisa envolver uma dimensão conceitual, e alguém só pode dar relatos confiáveis sobre tais experiências se for treinado a apresentar uma tendência ou disposição diante de certas condições e contextos. Como dissemos, a análise da "lógica do parece" indica um abandono da tese de conhecimento não estruturado - não se pode ter o conceito de "parecer verde" sem possuir os conceitos de "ser 
verde" ou "estar iluminado", isto é, conceitos que envolvem as condições do ambiente, os estados do percipiente etc. Portanto, rejeita-se a ideia de que o mundo impõe uma estrutura conceitual diretamente sobre o sujeito, que é, em síntese, a própria essência da ideia de "dadidade". Também abre-se caminho para uma "linguística transcendental", a tese de que as categorias básicas que estruturam os estados intencionais do sujeito racional são categorias que emergem da própria prática linguística. Em vista disso, a linguagem pública é indispensável na instituição e manutenção de esquemas conceituais. Finalmente, esta maneira de enxergar os conceitos e a exigência de justificação do conhecimento abrem espaço para uma epistemologia coerentista.

$\mathrm{O}$ argumento básico em favor do fundacionismo e do dado, e contra o coerentismo, é o risco de regresso ao infinito. $\mathrm{O}$ argumento básico em favor do coerentismo, e contra o fundacionismo e o dado, é que não há nenhum conhecimento que seja fundacional (não inferencial e autojustificável) em si mesmo. Sellars é claramente não fundacionalista, porque a crítica ao dado proíbe a aceitação de qualquer tipo de crença que seja por si mesma justificável. Mesmo relatos que envolvem as percepções dependem de outros relatos que o sustentem. Ou seja, o fundacionalista aceita algum conhecimento autojustificável e não inferencial; o coerentista o rejeita. Agentes que dominam uma linguagem pública são treinados a oferecer relatos seguros e confiáveis de suas experiências sensoriais não porque estas experiências lhes oferecem conhecimentos estruturados, e sim porque o agente pode inferir a partir de certas experiências. Por exemplo, quando um usuário da linguagem aprende a afirmar que "o sol é amarelo" olhando para o sol, garante a validade deste relato e reúne condições que lhe permitem raciocinar (inferir) a partir disto. Assim, afirmar, olhando para o sol, que "o sol é amarelo" é um conhecimento não inferencial, mas justificado pela estrutura conceitual do sujeito que sustenta o relato. E, como a própria justificação é uma questão inferencial, não existe ao mesmo tempo um conhecimento não inferencial e autojustificável não inferencialmente. Relatos de percepção são não inferenciais, porém, justificados inferencialmente. Assim, a "justificação" é o conceito fundamental da explicação sobre o que o conhecimento deve ser, embora tal conceito seja entendido diferentemente por fundacionalistas e coerentistas, gerando alguns dos equívocos aqui mencionados.

Ora, conteúdos intencionais são sempre entendidos em termos da função que eles ocupam na economia cognitiva do agente, desde que sejam justificados adequadamente pela estrutura inferencial do sujeito de conhecimento. Todavia, Sellars não adere a um coerentismo absoluto. Ele busca conciliar os argumentos positivos extraídos tanto do coerentismo como do fundacionalismo, enquanto procura evitar as falhas e radicalismos de ambos. Em uma de suas afirmações mais citadas, discutidas e menos compreendidas, Sellars afirma: 


\begin{abstract}
Se eu rejeito a estrutura do empirismo tradicional, não é porque eu queira dizer que o conhecimento não tenha fundação [...] Existe certamente alguma razão na imagem do conhecimento humano como repousando sobre proposições - relatos de observação - que não repousam em outras proposições da mesma forma em que outras proposições repousam nelas. Por outro lado, eu quero insistir que a metáfora da 'fundação' é enganadora por nos impedir de ver que, se há uma dimensão lógica na qual outras proposições empíricas repousam em relatos de observação, existe uma outra dimensão na qual os últimos repousam nas primeiras. Acima de tudo, a figura é enganadora por causa do seu caráter estático. Parece que somos forçados a escolher entre a imagem de um elefante que repousa sobre uma tartaruga (o que suporta a tartaruga?) e a imagem de uma grande serpente hegeliana do conhecimento com a cauda em sua boca (onde ela inicia?). Nenhuma serve. Pois o conhecimento empírico, como a sua sofisticada extensão, a ciência, é racional, não por ter uma fundação, mas por ser um empreendimento auto-regulador que pode colocar qualquer afirmação em questão, embora não todas simultaneamente (SELLARS, 2008, pp. 82-3).
\end{abstract}

O que é preciso compreender é que Sellars adota um internalismo para justificar em que momento começa a articulação inferencial da experiência conceitual do agente. O fundacionalista tem razão em afirmar que o conhecimento perceptual é, de alguma maneira, basilar, mas o coerentista também está correto ao sugerir que tal conhecimento depende da organização estrutural que o justifica, que justifica a experiência. E qualquer conhecimento que pressupõe logicamente outro conhecimento é inferencial, de modo que não existe um conhecimento autojustificável e não inferencial, não existe o dado no seu sentido tradicional e fundacionalista. Como resultado, Sellars sugere uma reconciliação do coerentismo com o um fundacionalismo mínimo e trivial, garantindo a coerência sem negar algum tipo de "informação" não inferencial, causal, oferecida na experiência sensorial. Individualmente, versões de fundacionalismo e coerentismo são insatisfatórias; se combinadas adequadamente, elas permitem uma ideia de conhecimento dinâmico, seguro e incremental. A tartaruga e a serpente coexistem.

\title{
Conclusão
}

Segundo Sellars, a maneira tradicional de conceber a relação entre mente e mundo faz o dado parecer inevitável. O mito do dado resulta, assim, da confusão entre o modo como adquirimos o conhecimento e o modo como o justificamos, que deve ser sustentado em um discurso baseado em um espaço lógico, conceitual e inferencialmente estabelecido. O que for anterior a tal espaço é apenas um antecedente não cognitivo. Assim, a rejeição ao 
dado e a definição do "espaço lógico das razões" tornam possível uma reflexão sobre o conhecimento a partir de uma explicação social. Deste modo, Sellars adota um modelo epistemológico que reconhece a importância da afecção, mas evita o dado, e relaciona suas ideias a um modelo funcional e inferencialista do uso de conceitos no raciocínio do sujeito.

Um dos principais resultados da discussão sugerida por Sellars é a diferenciação do comportamento meramente respondente e da consciência conceitual situada no espaço racional. Animais e recém-nascidos tem, evidentemente, experiências sensoriais, porém, somente usuários da linguagem podem justificar as suas manifestações linguísticas e comportamentais que expressam tais experiências. Portanto, o conhecimento não é anterior ao uso da linguagem e não pode ser "dado" na experiência sensorial. Evidentemente, Sellars não acredita que algo mude na experiência de uma criança que aprendeu a dominar um jogo de uso de palavras; a sensação permanece a mesma, contudo, a aquisição da linguagem possibilita sua coerência inferencial. Antes da linguagem, as sensações não podem ser classificadas e relacionadas com conceitos, não podem participar do jogo racional de justificar e exigir justificações. Se existe um conteúdo obtido na percepção, que não é o resultado de uma inferência, ele também exige uma articulação inferencial, o que lhe impede a denominação de "dado". O conhecimento é baseado mais em conceitos de justificação e uso racional, a aplicação e o domínio de suas inter-relações, do que fundado em algo direto que é oferecido ao sujeito. Conhecer é um empreendimento social, incremental, autorregulável.

Vale mencionar, por fim, que as conclusões desenvolvidas por Sellars com a crítica ao dado são discutidas na segunda parte de Empirismo e Filosofia da Mente, através do "mito de Jones", que oferece uma explicação, sem envolver qualquer noção de dadidade, dos episódios internos (pensamentos e impressões dos sentidos) do sujeito. Este novo mito é um exemplo de filosofia do mental que não apela à ideia de dado e assimila as ideias discutidas neste trabalho, como a de conhecimento mediado pela linguagem, inferencial, holístico, normativo e intersubjetivo; em sua parte final, ele explica a experiência perceptiva, constituindo-se em uma das partes mais difíceis e ainda inexploradas do trabalho de Sellars. 


\section{Referências bibliográficas}

AUSTIN, J. L. Sentido e percepção. São Paulo: Martins Fontes, 2004.

AYER, A. J. Language. Truth and Logic. London: Penguim Books, 2001. The foundations of empirical knowledge. London: Macmillan, 1961.

DESCARTES, R. Meditações Metafísicas. Trad. de J. Guinsburg; Bento Prado Jr. São Paulo: Abril Cultural, 1973. Coleção Os Pensadores.

DEVRIES, W. A.; Triplett, T. Knowledge, Mind, and the Given: reading Wilfrid Sellars's "Empiricism and the Philosophy of Mind" including the complete text of Sellars's essay. Indianapolis/Cambridge: Hackett Publishing, 2000.

HUME, D. A Treatise of Human Nature. The Clarendon Edition of the Works of David Hume: A Treatise of Human Nature, Vol. 1. Norton, D. F; Norton, M. J. (Eds.). Oxford: Oxford University Press, 2007.

MAROLDI, M. M.; Linguagem, Comportamento e Mente no Mito de Jones de Wilfrid Sellars. Kinesis, v. 6, p. 89-105, 2014.

MCDOWELL, J. Mind and World. Cambridge, Ma: Harvard University Press, 1994.

PRICE, H. H. Perception. London: Methuen, 1932.

RYLE, G. The Concept of Mind. London: Hutchinson, 1975.

RUSSELL, B. The Problems of Philosophy. Oxford: Oxford University Press, 1997.

SELLARS, W. Empirismo e Filosofia da Mente. Com uma introdução de Richard Rorty e guia de estudos de Robert Brandom. Trad. de S. I. A. Stein. São Paulo: Vozes, 2008.

Science, Perception and reality. Atascadero (CA): Ridgeview Publishing Company, 1991. 